\title{
Comparison of Displacement Ventilation, Mixing Ventilation and Underfloor Air Distribution System
}

\author{
Shouhong Ren ${ }^{1, a}$, Shuo Tian ${ }^{2, b}$ and Xiangyi Meng ${ }^{3, c}$ \\ ${ }^{1}$ Department of College of Civil Engineering, Inner Mongolia University of Technology, \\ Aimin Street 49 , Hohhot,China \\ ${ }^{2}$ Department of College of Civil Engineering, Inner Mongolia University of Technology, \\ Aimin Street 49 , Hohhot,China \\ ${ }^{3}$ Department of College of Civil Engineering, Inner Mongolia University of Technology, \\ Aimin Street 49 , Hohhot,China \\ am13604717375_1@163.com, b1968906844@qq.com, '932924257@qq.com
}

\begin{abstract}
Keywords: Air Environment Controlling, Displacement Ventilation, Mixing Ventilation, Underfloor Air Distribution System
\end{abstract}

Abstract. At present, the scientific community attaches importance to the problem of indoor air quality and building energy conservation seriously, the people's requirement of indoor living environment is also improving constantly, improving the problem of air conditioning energy consumption of building energy consumption and the way of ventilation has been on the agenda.

In view of this situation, we researched and compared the principle, merit and demerit as well as applicable occasions of the displacement ventilation, mixing ventilation and underfloor air distribution. In the process of investigation and study, we found that the practical application of the air conditioning should be on the basis of different occasions and choose different way of ventilation accordingly, only then can we reduce the energy consumption of air conditioning, alleviate the problem of energy shortage and improve the indoor air quality.

\section{Introduction}

With the development of national economics in our country, the problem of the lack of energy is serious increasingly, the proportion of building energy consumption in our country is getting bigger and bigger, the energy consumption of the air conditioning is the main origin of buildings, so the energy conservation of the air conditioning has a broad prospect. In addition, in the modern society, people spend more time in buildings instead of outside, the people's requirements of indoor environment are higher and higher, the indoor air quality is gradually related to the interior personnel's physical health and work efficiency. With the appearance of mixing ventilation, displacement ventilation and underfloor air, there are different indoor air distribution. The extent of the improvement of indoor air quality is also different, only a deep understanding of their mechanism, distribution of temperature and humidity, air velocity, so we can choose the right means of ventilation for a particular occasion.

\section{Displacement Ventilation}

The mechanism of displacement ventilation. The displacement ventilation supplies air in a low speed from the bottom of the room, air flow moves up slowly in a state of the piston flow with the help of buoyancy. When air flow reaches a certain height, it'll produce turbulent region affected by the heat source and ceiling. Air distributor of displacement ventilation is usually close to the floor, generally the velocity of air supply is about $0.3 \mathrm{~m} / \mathrm{s}$, and it causes the mixture proportion of supply air flow and indoor air is very low. The difference in temperature of supply air is $2 \sim 4{ }^{\circ} \mathrm{C}$. Air sinks in low speed under the action of gravity, and slowly spreads, forming a thin air layer above the ground. Due to the effect of buoyancy, hot polluted air produced by indoor heat sources rises, and constantly mixes with the ambient air. Because of the entrainment phenomenon which the rising heat polluted 
air causes, the driving force from following fresh air and pumping action from outlet, the fresh air above the floor also moves up slowly, forming the upward piston flow. So, the polluted air in the work area is replaced by the subsequent fresh air. When the indoor air reaches a stable state, it forms two respects on temperature and concentration: the upper mixed area and the lower one-way flow clean area, the stratification of indoor air can ensure that the body is in the clean area, as well as the space above the body is not what we want to control, so in this way we can achieve the goal of energy saving.

The merits and demerits of displacement ventilation. Advantages are as follows: Good thermal comfort and the quality of indoor air; the low noise; Space feature and architectural design have good compatibility; wide adaptability and great flexibility; low energy consumption, less initial investment, low operating cost.

Disadvantages: in some cases, the displacement ventilation need to have larger air output. Because the temperature of supply air is high, indoor humidity must be effectively controlled; When Pollutant density is greater than air or is not associated with air, it is not suitable for displacement ventilation. Under the heavy load, the displacement ventilation system needs to send the cold wind, so the displacement ventilation does not apply to a warm climate. the performance of displacement ventilation depends on the height of the roof, so it does not apply to the space with high bottom.

From the dynamic analysis, for the air blower, cooling and heating energy consumption and carbon dioxide emissions, when using displacement ventilation, we need to pay attention to the followings:

Ignoring the requirement of the new air volume to achieve a small amount of energy saving will damage the indoor air quality.

Compared with the dilution mixing ventilation, displacement ventilation can save more energy.

Compared with the constant flow system, using displacement ventilation on the basis of variable flow systems can save $43 \%$ energy consumption.

The indoor air quality. In the workspace, the existence of displacement ventilation system makes the air rise above staff, pollutants flow up vertically from pollution sources without cross infection. Although the layout in workspace will affect indoor air distribution, which produces turbulence in the lower area that prevents pollutants from spreading outwards. This area is not in the human breathing zone, so it will not affect the quality of the air that the humans need.

\section{Mixing Ventilation}

The basic principles of mixing ventilation. Traditional mixing ventilation controls the density of indoor pollutants by bringing in enough outdoor air to dilute emissions from indoor sources uniformly.

There are three kinds of principles of mixing ventilation:

The characteristic of trading off mechanical ventilation and natural ventilation is that we use natural ventilation when the temperature outside the building aren't problem and mechanical ventilation can be used when outdoor temperature is above standard. This pattern is appropriate for areas with four distinctive seasons.

Natural ventilation can coexist with mechanical systems in a hybrid mode. This system may use fan to increase the wind pressure at points to avoid insufficient driving force. This pattern can be used in areas with a moderate climate.

The mechanical ventilation under hot action and wind pressure is main use of power generated by the ventilators all the time with the help of thermal and air pressure. This mode can be used in cold region or hot region.

The merits and demerits of mixing ventilation. The mixing ventilation has following merits: Energy conservation. According to the investigation and analysis, the traditional ventilation is four times more power-wasting than the mixing ventilation.

The system can produce more cooling capacity without blowing feeling. 
The natural ventilation used in mixing system help improve the performance of traditional air conditioning that cause lots of pollution in the fresh air.

It can turn the vertical temperature gradient into the uniform distribution of temperature.

The mixing ventilation has following demerits:

The turbulence in people active region can be strengthened, which causes the sense of coldness.

The uniform air velocity is high in working space.

The low efficiency of ventilation causes high pollutant concentrations that can remain in the air for long periods.

\section{The Underfloor Air Distribution System}

The basic principles of under-floor air distribution system. The updraft from underground with setting velocity mixing quickly with air from working space can control temperature in working area. When the air arrives in non-work space, some of them is exhausted from exhaust outlet, others is processed by under-floor fan after mixing with fresh air. Because of high speed of air-out, the air stratification is formed in upper space.

The under-floor air distribution system is a new style of air-supply. It regards under-floor space as (UF) plenum. According to human's needs, the air after secondary mixing is directly sent to working space by air diffuser.

The merits of under-floor air distribution system. The air diffuser doesn't need to connect with the vent pipe. The size of air diffuser is the same as the module of floor, so it can be placed everywhere, which can meet the needs of different layouts and functions in modern office. Compared with traditional system, it is convenient for care and maintenance.

From the introduction, with using under-floor air supply system, the air age can be decreased, the efficient of air change and ventilation are increased, and the indoor air quality is significantly improved.

By adjusting the direction of fresh air and amount of air supply from users, the favorable thermal comfort is able to be offered.

Because of only maintaining the environmental parameters of working space, the air supply and fan heat are decreased and the efficiency of refrigerating machine is increased, the consumption of fan energy, cold and heat source energy are reduced in under-floor air supply system.

\section{The Comparison of the Three Kinds of Ventilation Manner}

From the introduction, the under-floor distribution and displacement ventilation have something in common. They all use under-floor air distribution and form the heat lamination, which help energy conservation and improve the indoor air quality. Starting with this mechanism, the supply air in the under-floor distribution is the source of power and footage. But in the displacement ventilation, it is just a power producer. From the results, the displacement ventilation creates air supply condition; the mixing ventilation forms air exhaust in whole space. From the distribution of temperature and concentration, the displacement ventilation uses fresh air to displace the polluted air in working space. But the mixing ventilation controls the density of indoor pollutants by bringing in enough outdoor air to dilute emissions from indoor sources uniformly.

The supply air velocity is the key of distinction. The mixing ventilation requires high supply air velocity to form air-jet, which can help mix the fresh air with the indoor air to achieve the goal that temperature and concentration can reach the agreement. When the supply air velocity is reduced to the level that the height of air-jet is the same as room's. The mixing ventilation becomes the under-floor distribution. At this time, the supply air just mixes with the air in working space and can be responsible for the load of working space to save energy. And the displacement ventilation is the result of reducing the supply air velocity to some level. The fresh air can replace the polluted air by falling tendency, and rose with polluted air. 


\section{Conclusions}

According to comparison, three kinds of air supply are similar in mechanism. But their ranges of application are different which leads to different results. A good result is affected by both the pattern of air supply and system design. So we should choose the appropriate mode of ventilation for different places in actual life.

\section{References}

[1] Hanqing Wang: Ventilation Engineering (Beijing: Mechanical industry press,2007), in Chinese.

[2] Wanbin Xiong: Ventilation and Dust Removal and Pneumatic Conveying (Beijing: Chemical industry press,2008), in Chinese.

[3] Zhonghua Tang: Ventilation and Dust Removal and Purification. (Beijing: China architecture \& building industry press,2009), in Chinese.

[4] Pingfang Hu: The Building Ventilation and Air Conditioning New Technology and Its Application(Beijing: China electric power press,2010), in Chinese.

[5] Yijian Sun: Industrial Ventilation(Beijing: China architecture \& building industry press,1994) ,in Chinese.

[6]The Ministry of Construction of the People's Republic of China:Code of Acceptance for Construction Quality of Ventilation and Air Conditioning Works (GB50243-2002) (Beijing: 2002), in Chinese.

[7]Xi Yuan,Qingyan Chen, L.Glicksman:A Critical Review of Displacement Ventilation[J]. ASHRAE Transaction, 1998, 104

[8]GuoBing Ma,Xuemeng Wei:Analysis and Research of Displacement Ventilation Air Distribution and Influencing Factors [J].Building Heat Ventilation and Air Conditioning,2002,21(3):5-12

[9] Matsunawa K,Lizuka H, Tanabe S:Development and Application of An underfloor Air-condicationing System with Improved Outlets for "smart" building in Tokyo [J]. ASHRAE Transaction, 1995; 101(2):887-901

[10] Qiangmin Li: Principle, Design and Application of Displacement Ventilation[J].HVAC,2000, 30(5):41-46,in Chinese.

[11] Tom Webster, Fred Bauman:Underfloor Air Distribution.Thermal Stratification [J]. ASHRAE Journal,2002,(5):28-36 